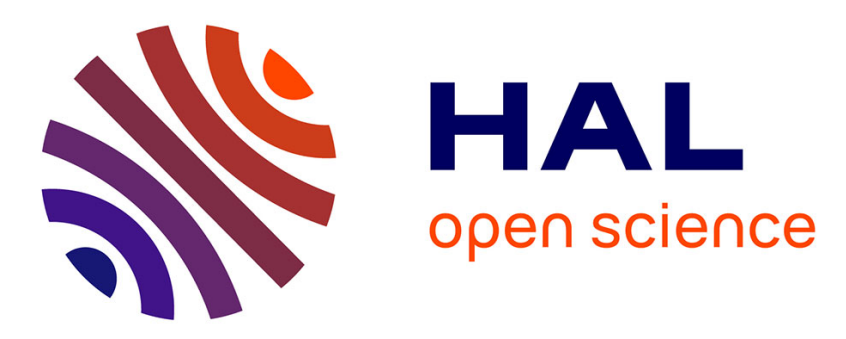

\title{
Self-excited instabilities in plasmas containing dust particles (dusty or complex plasmas)
}

Maxime Mikikian, Marjorie Cavarroc, Lénaïc Couëdel, Yves Tessier, Laïfa Boufendi

\section{- To cite this version:}

Maxime Mikikian, Marjorie Cavarroc, Lénaïc Couëdel, Yves Tessier, Lä̈fa Boufendi. Self-excited instabilities in plasmas containing dust particles (dusty or complex plasmas). Chaos, Complexity and Transport: Theory and Applications, Jun 2007, Marseille, France. pp.217. hal-00332695

\section{HAL Id: hal-00332695 https://hal.science/hal-00332695}

Submitted on 21 Oct 2008

HAL is a multi-disciplinary open access archive for the deposit and dissemination of scientific research documents, whether they are published or not. The documents may come from teaching and research institutions in France or abroad, or from public or private research centers.
L'archive ouverte pluridisciplinaire HAL, est destinée au dépôt et à la diffusion de documents scientifiques de niveau recherche, publiés ou non, émanant des établissements d'enseignement et de recherche français ou étrangers, des laboratoires publics ou privés. 


\title{
SELF-EXCITED INSTABILITIES IN PLASMAS CONTAINING DUST PARTICLES (DUSTY OR COMPLEX PLASMAS)
}

\author{
M. MIKIKIAN*, M. CAVARROC, L. COUËDEL, Y. TESSIER, L. BOUFENDI \\ GREMI, Groupe de Recherches sur l'Energétique des Milieux Ionisés, UMR6606, \\ CNRS/Université d'Orléans, 14 rue d'Issoudun, BP6744, 45067 Orléans Cedex 2, \\ France \\ *E-mail: maxime.mikikian@univ-orleans.fr
}

\begin{abstract}
Dusty plasmas are complex systems where new phenomena arise from the presence of solid dust particles inside a plasma. Dust particles acquire a negative charge by attaching free electrons and are thus trapped in the plasma. This charge loss can be drastic for the plasma equilibrium and instabilities can appear due to the strong interdependence between the dust particle cloud and the plasma. In this paper, various types of self-excited instabilities consisting in regular or chaotic oscillations, are presented. They are obtained in low pressure radio-frequency discharges where dust particles are grown by using a reactive gas or by sputtering a surface exposed to the plasma. The complex evolution scheme of these instabilities is brought to the fore thanks to various diagnostics.
\end{abstract}

Keywords: Dust; Plasma; Instabilities; Nanoparticle; Fourier analysis.

\section{Introduction}

Dusty plasmas ${ }^{1,2}$ are partly ionized gases (mixture of neutral atoms and/or molecules, positive and/or negative ions, free electrons) containing solid dust particles with sizes ranging from few nanometers to centimeters. These media are observed in astrophysics (comet tails, planetary atmospheres) and also in industry where dust particles are usually fatal for the processes in microelectronics but useful to build small objects in nanotechnologies or to design nanostructured materials with interesting properties. Thermonuclear fusion is also concerned by dust production due to wall erosion.

To study these media, dust particles are either artificially injected in the plasma or formed using reactive gases or a target sputtered by the plasma ion bombardment. These methods lead to the formation of a dense cloud of submicron dust particles filling the whole plasma volume. 
Reactive gases are often used due to their ability to easily form dust particles by following a succession of different growth phases. One of the most studied and well-known reactive gas is silane $\left(\mathrm{SiH}_{4}\right) \cdot{ }^{3-7}$ The interest for silane based plasmas is related to their implication in microelectronics and nanotechnology. Indeed, in the late 1980s, dust particle formation in the gas phase has been evidenced in reactors used for silicon-based device fabrication. ${ }^{3,8}$ Cleanliness is often a major requirement for microelectronics processes and a lot of studies began for understanding dust particle formation and growth in order to avoid their deposition. More recently, silicon nanocrystal formation ${ }^{9}$ became of high interest for their incorporation in thin films in order to improve film properties. For example, the use of silicon nanocrystals in solar cell technology enhances the optoelectronic properties of the deposited films. ${ }^{10}$ In nanotechnology, single electron devices (SED) like transistors or memories can also be built, thanks to these crystalline nanoparticles. ${ }^{11}$ Dust particle formation in hydrocarbon-based gases like methane $\left(\mathrm{CH}_{4}\right)^{12,13}$ or acetylene $\left(\mathrm{C}_{2} \mathrm{H}_{2}\right)^{12-15}$ has also a high industrial implication for deposition of diamond-like carbon (DLC) films ${ }^{16}$ or nanocrystalline diamond ${ }^{17}$ with unique properties like extreme hardness. Hydrocarbon gases are also of great interest for the astrophysical community dealing with planet atmospheres like Titan, where dust particles are created due to the presence of methane. ${ }^{18}$

Dust particle production can also be achieved by material sputtering. ${ }^{19-21}$ This phenomenon occurs in industrial reactors or in fusion devices $^{22}$ like Tore Supra ${ }^{23}$ as well where graphite walls can be severely eroded by ion bombardment. Produced dust particles can strongly limit performances of the fusion plasma and raise radio-toxicity issues due to tritium retention. This aspect is of great importance for the future ITER reactor.

Once dust particles reach a few nanometers in size, they are trapped in the plasma due to the negative charge they acquire by attaching free electrons. ${ }^{24-27}$ This charge loss can be drastic for the plasma equilibrium and instabilities can appear due to the strong interdependence between the dust particle cloud and the plasma. Various types of low-frequency instabilities (from few $\mathrm{Hz}$ to few $\mathrm{kHz}$ ) are observed (with various frequencies and shapes) either during dust particle growth process ${ }^{20,28-30}$ or once the dust cloud is completely formed. ${ }^{31,32}$ In this last case, instabilities are related to the presence of a dust-free region in the plasma center. This region, named "void", exhibits successive contractions and expansions phases. This instability is usually named "heartbeat" instability due to this characteristic behavior. 


\section{Instabilities during dust particle growth}

In this section, instabilities occurring during the dust particle growth process are analyzed. These dust particles are produced in two different experimental setups and by using material sputtering or silane diluted in Ar.

\subsection{Dust particles formed by sputtering}

Dust particle growth instabilities ${ }^{29}$ (DPGI) typically appear a few tens of seconds after plasma ignition. At this stage, dust particles have grown to a typical size of few tens of nanometers. DPGI appearance is well observed on different diagnostics like electrical and optical measurements. These instabilities follow a well-defined succession of phases as observed in electrical measurements shown in figure 1(a). In this figure, the beginning of DPGI is detected around $40 \mathrm{~s}$ and successive phases are numbered from 1 to 7 . These different phases are better evidenced by performing a Fourier analysis of the electrical signals. A typical spectrogram is given in figure 1(b). In order to emphasize small ordered domains, the spectrogram intensity has been normalized inside each $100 \mathrm{~s}$ range (from 0 to $100 \mathrm{~s}$ intensity has been normalized to its maximum value inside this time domain and so on). We can identify seven different regimes:

- Three ordered phases $\mathrm{P} 1, \mathrm{P} 2, \mathrm{P} 3$ (from $\simeq 40 \mathrm{~s}$ to $\simeq 80 \mathrm{~s}$ ).

- Chaotic phase $\mathrm{P} 4$ (from $\simeq 80 \mathrm{~s}$ to $\simeq 405 \mathrm{~s}$ ).

- High frequency phase P5 (from $\simeq 405 \mathrm{~s}$ to $\simeq 435 \mathrm{~s}$ ).

- Chaotic phase becoming more and more regular P6 (from $\simeq 435 \mathrm{~s}$ to $\simeq 600 \mathrm{~s})$.

- Regular oscillation phase $\mathrm{P} 7$ (from $\simeq 600 \mathrm{~s}$ to $\simeq 680 \mathrm{~s}$ )

Instabilities begin with regular oscillations (P1, P2, P3) followed by a long chaotic regime (P4). This chaotic phase suddenly ends with a high frequency phase (P5) and starts again (P6) becoming more and more ordered. Finally, the system reaches a regular phase (P7) that can be sustained for a long time (in the example given here the plasma has been switched off at $680 \mathrm{~s}$ ). The P1 and P2 phases are short and are not detected in all experiments while the P3 phase lasts longer and is regularly observed. The three phases are well separated and evolve as a function of time. In figure $2(\mathrm{a})$, the $\mathrm{P} 1$ phase is characterized by wide separated peaks with a mean frequency of about $40 \mathrm{~Hz}$. The transition from P1 to P2 corresponds to the growth of two small peaks between these higher amplitude patterns. The small peaks continue to grow (P2 phase) and the higher amplitude ones 


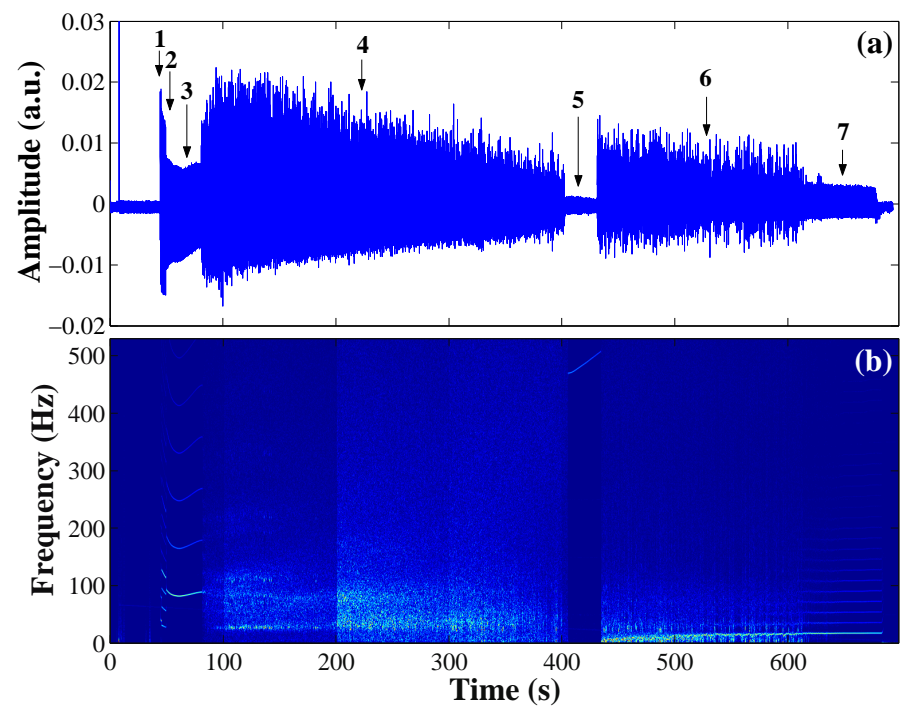

Fig. 1. Dust Particle Growth Instabilities: the different phases observed on (a) electrical measurements, (b) FFT of (a).

decrease. Finally, all peaks reach the same amplitude characterizing the P3 phase. The frequency of the $\mathrm{P} 3$ phase is then approximately three times the P2 frequency (around $94 \mathrm{~Hz}$ ).

The chaotic regime $\mathrm{P} 4$ (after $80 \mathrm{~s}$ ) is characterized by less ordered patterns and a strong increase in DPGI amplitude. Then, the amplitude slowly decreases during the whole phase. $\mathrm{P} 4$ is also characterized by structured oscillations appearing in a transient manner as shown in figure 2(b). These structured regions are identified by some bright spots on electrical and optical spectrograms. On time series they appear as bursts of order. During the chaotic regime, structured oscillations in electrical signals always appear following a three peak structure (for example between $94 \mathrm{~s}$ and 94.04 $\mathrm{s}$ in figure 2(b)) that could be related to the three peaks observed in the P2 phase. Indeed, it could be a reemergence of this phase during the chaotic regime. In some experiments, the chaotic regime is suddenly interrupted by a strong frequency change (at $405 \mathrm{~s}$ in figure 1). Indeed, DPGI turn into low-amplitude and high-frequency (around $500 \mathrm{~Hz}$ ) oscillations. After the high-frequency phase, a second chaotic regime is usually observed. It corresponds to a phase similar to $\mathrm{P} 4$ but with more and more ordered regions. The final step of DPGI often corresponds to a regular oscillation phase characterized by a spectrogram with a typical frequency around 18 
Hz. This regular oscillation is similar to what is obtained during the heartbeat instability, which corresponds to regular contractions and expansions of the void size. ${ }^{21,32}$

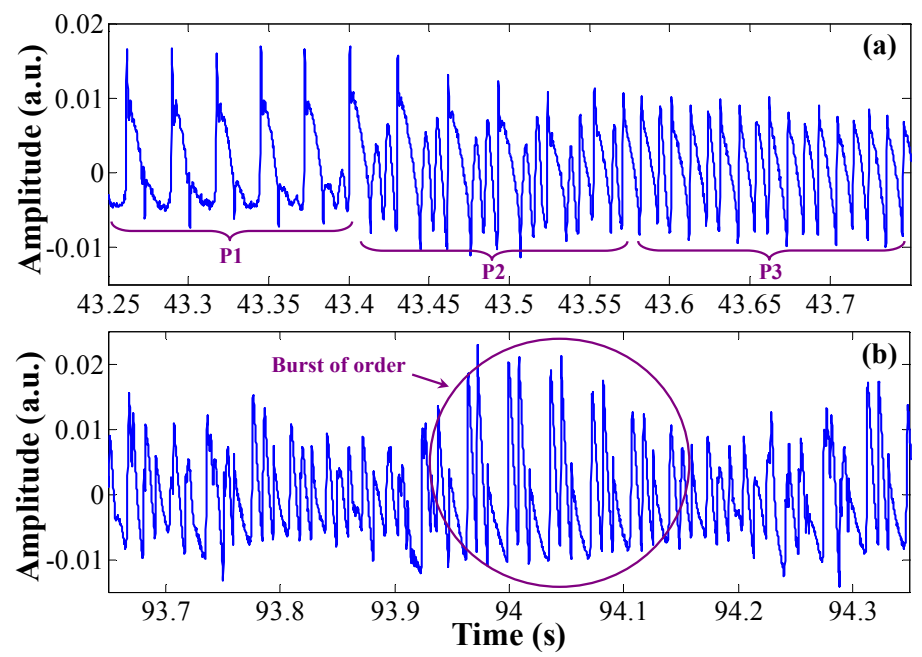

Fig. 2. (a) Transitions between the first three organized phases, (b) burst of order during the chaotic regime.

\subsection{Dust particles formed by reactive gases}

In silane based plasmas, the dust particle growth follows specific steps. When dust particle size reaches about $2 \mathrm{~nm}$, these clusters tend to agglomerate to form bigger size dust particles. When this aggregation occurs, the amount of plasma electrons lost on dust particle surface is suddenly changed. This drastic change leads to plasma instabilities ${ }^{9,30}$ as observed on the electrical measurements in figure 3(a)-(b). The corresponding time evolution of the instability frequency is given in figure 3(c). We can first observe an increase of the frequency that could correspond to the onset of the instability. Once the instability is established, the frequency decreases until the end of the phase where it becomes difficult to define.

In some very specific conditions a particular case of the instability was observed. Figure 4 shows the shape of the instability in this case. In the first part, it behaves in the same way as the "common" instability, then it finishes before briefly restarting. The second part seems to be a sort of replica of the end of the first part, with exactly the same frequencies. This phenomenon is 

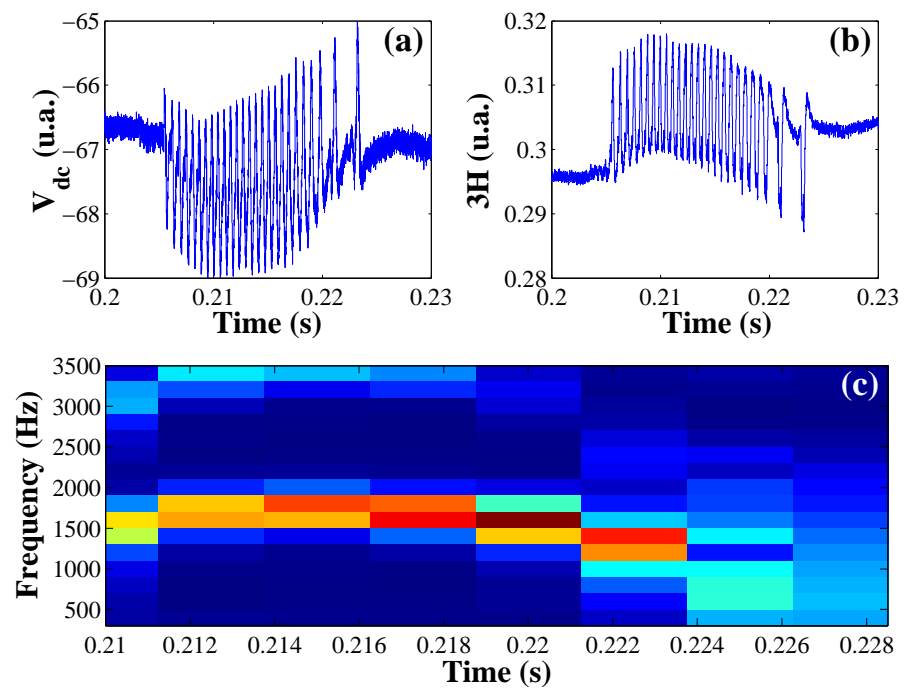

Fig. 3. Aggregation instability observed on electrical diagnostics (a) $\mathrm{V}_{d c}$, (b) $3 \mathrm{H}$, (c) FFT of (b).

highly sensitive to the operating conditions, appearing only for a very tight range of rf power and silane flow rate. This particular case of the instability seems to correspond to dust critical formation conditions, as the slightest modification of one of the parameters leads to the disappearance of the phenomenon. It underlines the threshold dependence of this instability.

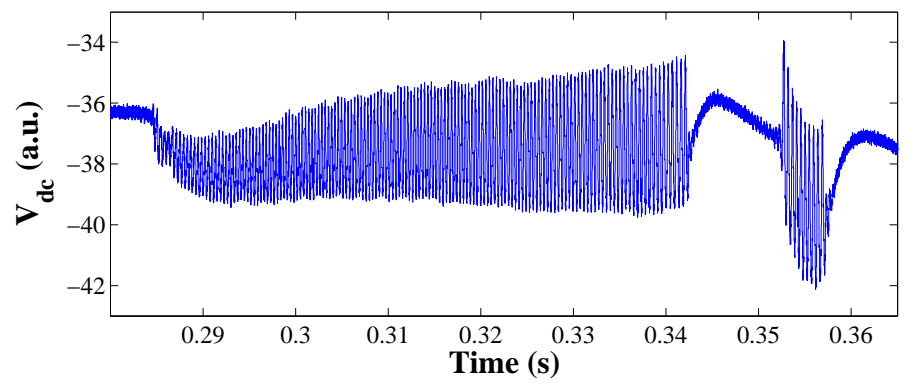

Fig. 4. Particular case of the aggregation instability: the instability stops and briefly restarts.

As long as silane is provided in the discharge, the dust particle growth continues as a cyclic phenomenon. Other kinds of instabilities are thus ob- 
served. As the mean size of dust particles trapped in the discharge is higher, characteristic frequencies are smaller than for the aggregation instability $(<100 \mathrm{~Hz}$ instead of few $\mathrm{kHz})$. Observed instabilities are related to the formation of new generations of particles, growing in the discharge center and pushing out the older generation of bigger size dust particles. These instabilities are characterized by two phases: a less-ordered and a highordered. The transition between these two regimes is sudden as observed in figure 5. The less-ordered regime corresponds to low amplitude noisy oscillations while the high-ordered one has higher amplitude and better defined oscillation frequency.

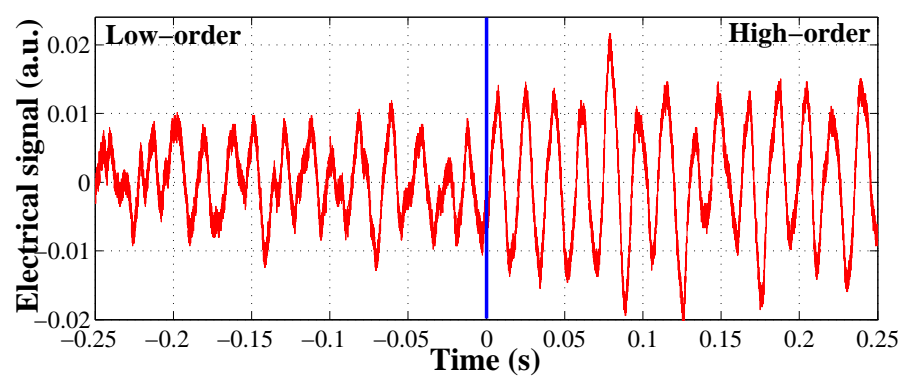

Fig. 5. Transition between the two characteristic phases (less and high ordered phases) of successive generation instabilities.

\section{Instabilities of the grown dust cloud}

In the sputtering discharge, successive generations of dust particles are not systematically obtained like in silane discharges. Thus, situations with a stable cloud of trapped dust particles can be obtained. Nevertheless, a dustfree region is often observed in the dust cloud center and is caused by the different forces acting on dust particles. This egg-shape region called "void" can exhibit self-excited oscillations ${ }^{31,32}$ of its size with typical frequencies about few tens of $\mathrm{Hz}$. Near the instability threshold or just before it stops, a transition regime characterized by "failed peaks" on both electrical and optical signals can be observed. Indeed, the oscillation pattern shows the occurrence of lower amplitude oscillations intercalated between two main oscillations. This phenomenon is repeated with more and more failed peaks and finishes by the instability stop. Figure 6 shows a transition between 1 and 2 failed peaks in the optical signal. The number of failed peaks increases $(>10)$ and then the instability stops (figure $7(\mathrm{a})$ ). 


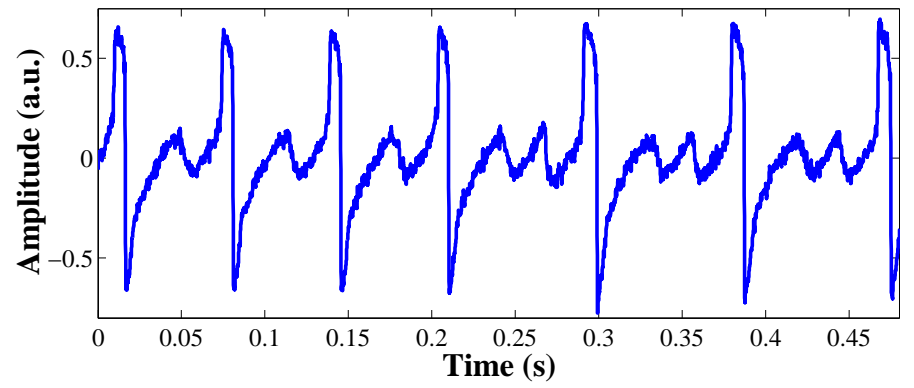

Fig. 6. Last beats of the instability: more and more failed peaks appear before the instability stops. The transition between one and two failed peaks is shown.
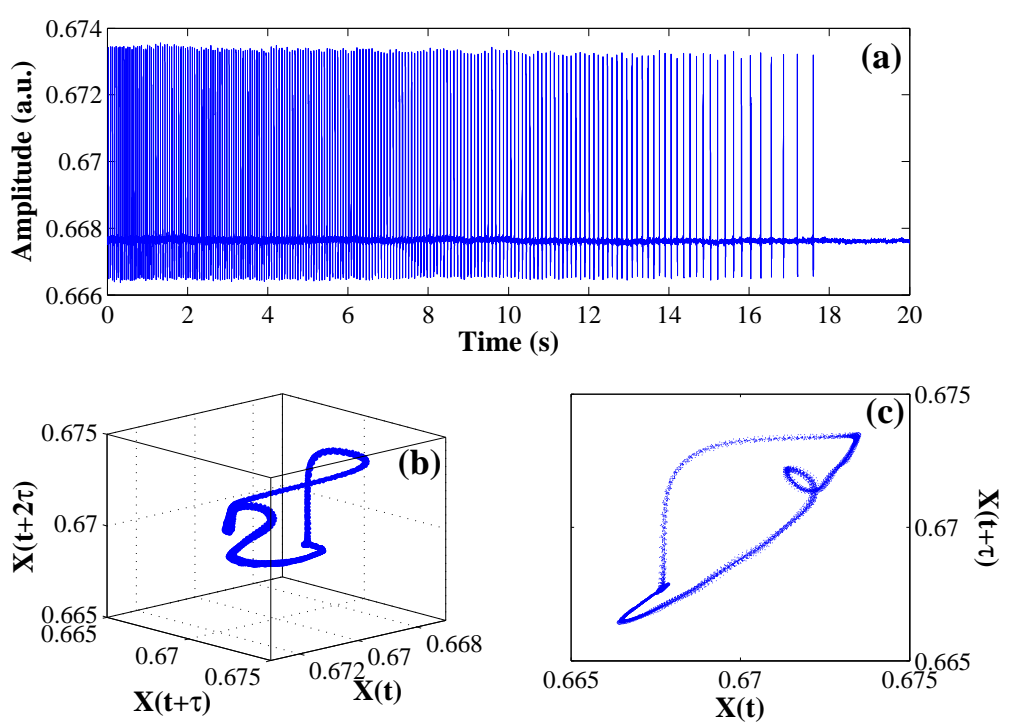

Fig. 7. Slow evolution of the heartbeat instability toward its end: (a) more and more failed peaks until the stop around $18 \mathrm{~s}$, (b) 3D and (c) 2D phase spaces.

As observed for other instabilities (figure 4), this behavior underlines the threshold dependence of this instability and the way it evolves toward its end. This alternation of failed and main peaks seems to correspond to mixed-mode oscillations often encountered in chemical systems or neuronal dynamics. The $3 \mathrm{D}$ and $2 \mathrm{D}$ phase spaces corresponding to the time series presented in figure 7 (a) are plotted in figure $7(\mathrm{~b})$-(c). These attractors have been obtained by using an appropriate time delay calculated using the mutual information method. 


\section{Acknowledgments}

The PKE-Nefedov chamber has been made available by the Max-PlanckInstitute for Extraterrestrial Physics, Germany, under the funding of DLR/BMBF under grants No.50WM9852. We would like to thank S. Dozias for electronic support and J. Mathias for optical support. This work was partly supported by CNES under contract 02/CNES/4800000059.

\section{References}

1. A. Bouchoule, Dusty Plasmas : Physics, Chemistry and Technological Impacts in Plasma Processing (Wiley, Chichester, 1999).

2. P. K. Shukla and A. A. Mamun, Introduction to Dusty Plasma Physics (Institute of Physics, Bristol, 2002).

3. R. M. Roth, K. G. Spears, G. D. Stein and G. Wong, Appl. Phys. Lett. 46, p. 253 (1985).

4. Y. Watanabe, M. Shiratani, Y. Kubo, I. Ogawa and S. Ogi, Appl. Phys. Lett. 53, p. 1263 (1988).

5. A. Bouchoule, A. Plain, L. Boufendi, J.-P. Blondeau and C. Laure, J. Appl. Phys. 70, p. 1991 (1991).

6. A. Howling, C. Hollenstein and P. J. Paris, Appl. Phys. Lett. 59, p. 1409 (1991).

7. A. Bouchoule, L. Boufendi, J. Hermann, A. Plain, T. Hbid, G. Kroesen and W. W. Stoffels, Pure Appl. Chem. 68, p. 1121 (1996).

8. G. S. Selwyn, J. Singh and R. S. Bennett, J. Vac. Sci. Technol. A 7, p. 2758 (1989).

9. M. Cavarroc, M. Mikikian, G. Perrier and L. Boufendi, Appl. Phys. Lett. 89, p. 013107 (2006).

10. P. Roca i Cabarrocas, P. Gay and A. Hadjadj, J. Vac. Sci. Technol. A 14, p. 655 (1996).

11. A. Dutta, S. P. Lee, Y. Hayafune, S. Hatatani and S. Oda, Jpn. J. Appl. Phys. 39, p. 264 (2000).

12. C. Deschenaux, A. Affolter, D. Magni, C. Hollenstein and P. Fayet, J. Phys. D: Appl. Phys. 32, p. 1876 (1999).

13. S. Hong, J. Berndt and J. Winter, Plasma Sources Sci. Technol. 12, p. 46 (2003).

14. I. Stefanović, E. Kovačevic, J. Berndt and J. Winter, New. J. Physics 5, p. 39 (2003).

15. K. De Bleecker, A. Bogaerts and W. Goedheer, Phys. Rev. E 73, p. 026405 (2006).

16. J. Robertson, Mater. Sci. Eng. R 37, p. 129 (2002).

17. D. Zhou, T. G. McCauley, L. C. Qin, A. R. Krauss and D. M. Gruen, J. Appl. Phys. 83, p. 540 (1998).

18. C. Szopa, G. Cernogora, L. Boufendi, J. J. Correia and P. Coll, Planet. Space Sci. 54, p. 394 (2006). 
19. B. Ganguly, A. Garscadden, J. Williams and P. Haaland, J. Vac. Sci. Technol. A 11, p. 1119 (1993).

20. G. Praburam and J. Goree, Phys. Plasmas 3, p. 1212 (1996).

21. M. Mikikian, L. Boufendi, A. Bouchoule, H. M. Thomas, G. E. Morfill, A. P. Nefedov, V. E. Fortov and the PKE-Nefedov Team, New J. Phys. 5, p. 19 (2003).

22. J. Winter, Plasma Phys. Control. Fusion 40, p. 1201 (1998).

23. C. Arnas, C. Dominique, P. Roubin, C. Martin, C. Brosset and B. Pégourié, J. Nucl. Mater. 353, p. 80 (2006).

24. B. Walch, M. Horanyi and S. Robertson, IEEE Trans. Plasma Sci. 22, p. 97 (1994).

25. C. Arnas, M. Mikikian and F. Doveil, Phys. Rev. E 60, p. 7420 (1999).

26. A. A. Samarian and S. V. Vladimirov, Phys. Rev. E 67, p. 066404 (2003).

27. L. Couëdel, M. Mikikian, L. Boufendi and A. A. Samarian, Phys. Rev. E 74, p. 026403 (2006).

28. D. Samsonov and J. Goree, Phys. Rev. E 59, p. 1047 (1999).

29. M. Mikikian, M. Cavarroc, L. Couëdel and L. Boufendi, Phys. Plasmas 13, p. 092103 (2006).

30. M. Cavarroc, M. C. Jouanny, K. Radouane, M. Mikikian and L. Boufendi, J. Appl. Phys. 99, p. 064301 (2006).

31. M. Mikikian and L. Boufendi, Phys. Plasmas 11, p. 3733 (2004).

32. M. Mikikian, L. Couëdel, M. Cavarroc, Y. Tessier and L. Boufendi, New J. Phys. 9, p. 268 (2007). 